\title{
Erratum to: Microstructural Characterization of a Polycrystalline Nickel-Based Superalloy Processed via Tungsten-Inert-Gas-Shaped Metal Deposition
}

\author{
DANIEL CLARK, MARTIN R. BACHE, and MARK T. WHITTAKER
}

DOI: $10.1007 / \mathrm{s} 11663-011-9489-2$

(c) The Minerals, Metals \& Materials Society and ASM International 2011

Erratum to: METALLURGICAL AND MATERIALS

TRANSACTIONS B, 2010, Vol. 41B,

pp. 1346-1353

DOI: $10.1007 / \mathrm{s} 11663-010-9410-4$

THE publisher regrets that an error occurred in the title of this article.

The correct title of this article is: "Microstructural Characterization of a Polycrystalline Nickel-Based Superalloy Processed via Tungsten-Inert-Gas-Shaped Metal Deposition".

DANIEL CLARK, Specialist Welding Engineer, is with the RollsRoyce plc, Derby, DE24 8BJ, England. MARTIN R. BACHE, Professor, and MARK T. WHITTAKER, RCUK Research Fellow, are with the School of Engineering, Swansea University, Swansea, SA2 8PP Wales, UK. Contact e-mail: m.t.whittaker@swansea.ac.uk

The online version of the original article can be found under doi:10.1007/s11663-010-9410-4.

Article published online February 3, 2011. 